\title{
Aetiology and management of the 'detached' rectus muscle
}

\author{
Caroline J MacEwen, John P Lee, Peter Fells
}

\begin{abstract}
The clinical features and management of 17 cases of detached extraocular muscles are described. They are classified into four groups: (1) the muscle which is cut and lost during squint surgery, (2) the muscle which breaks during squint surgery, (3) the muscle which slips following squint surgery, and (4) the muscle which is damaged during facial or orbital trauma. The prognosis for group 1 is poor whereas groups $2-4$ have a good chance of successful muscle relocation.
\end{abstract}

One of the most serious complications of squint surgery is loss of one of the rectus muscles. This may occur either during the surgical procedure itself or in the immediate postoperative period when the muscle slips from its new (recessed or resected) insertion. ${ }^{12}$. In addition, extraocular muscles may become traumatically detached from the globe when they rupture or are transected as the result of any injury or during the course of retinal detachment, orbital, or strabismus surgery. ${ }^{34}$

In this paper we, firstly, report our experience of 17 cases in which one of the rectus muscles became detached from the globe; secondly, classify the different types of muscle loss; and thirdly, discuss the clinical features, management, and prognosis of such cases.

Patients and methods

The patients included in this series are all those

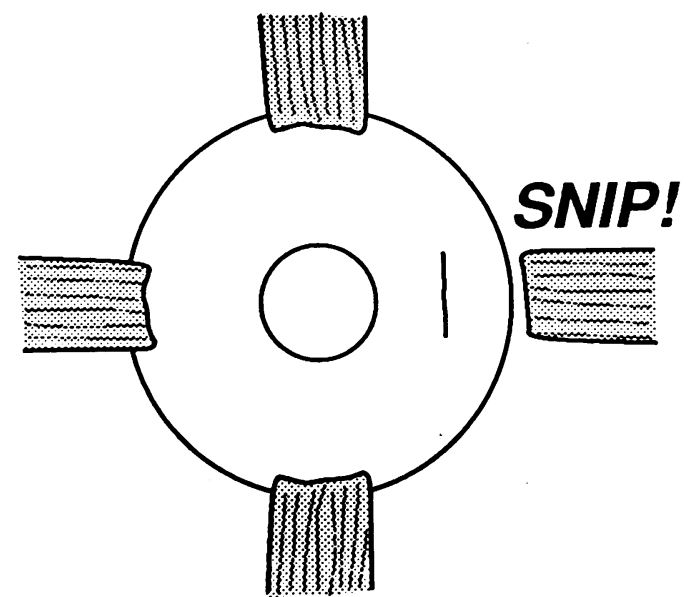

Figure 1 The muscle which is lost during surgery is

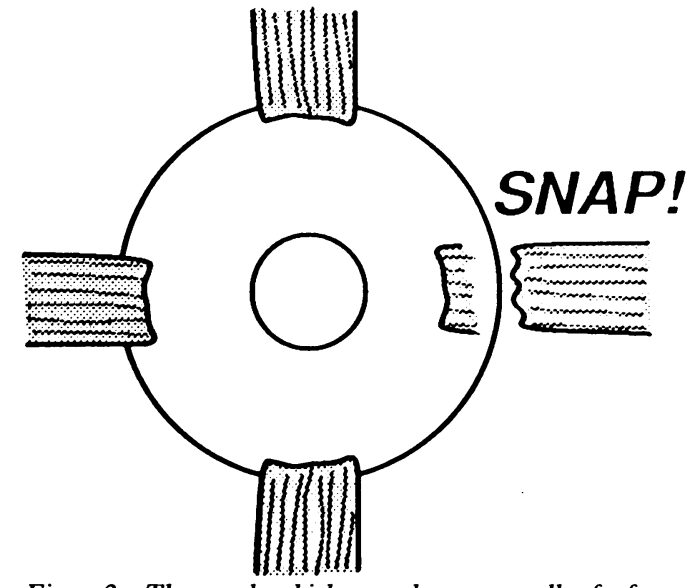

Figure 2 The muscle which snaps leaves a small tuft of insertion attached to the eye.

who presented to or were referred to any of the authors with a detached rectus muscle. These patients were referred either at the time of surgery, postoperatively, or in the period following injury.

Patients belonged to one of the following four groups.

GROUP 1

Cases in which the muscle was inadvertently cut free from the globe and lost during squint surgery (Fig 1). In each instance the muscle had become completely detached from the globe and free from any suture attachments during the course of an otherwise uncomplicated resection/

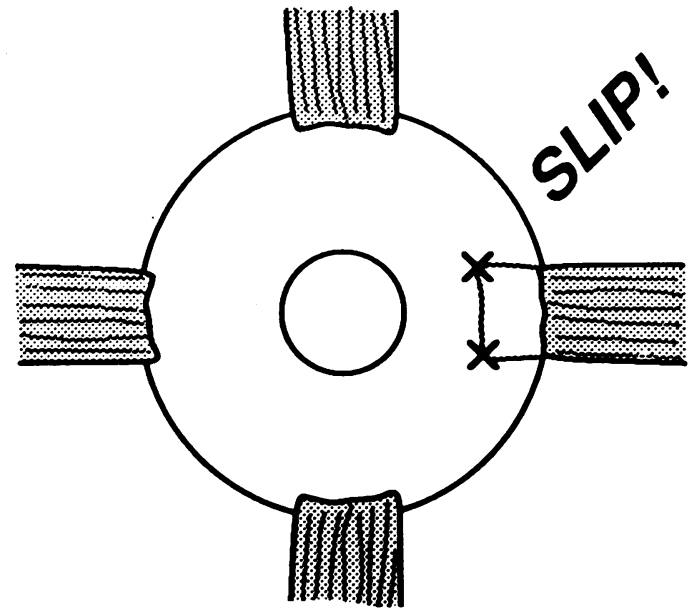

Figure 3 The slipped muscle contracts within its capsule remaining in contact with the eye via this attachment. completely detached from the eye.

Moorfields Eye Hospital, City Road, London JP Lee

Correspondence to:

Accepted for publication
} 
recession procedure. These muscles could not be re-located by the referring surgeon.

GROUP 2

Cases in which one of the muscles traumatically snapped during the course of squint surgery (Fig 2 ). The muscle was not surgically cut from the globe but broke while being held on the squint hook. In some cases the affected muscle had been damaged by previous surgery, trauma, or disease.

GROUP 3

Cases in which the muscle 'slipped' in the early postoperative period (Fig 3). In all cases the involved muscle appeared to be securely attached to the globe at the end of the initial squint operation. However immediately postoperatively it became apparent that one of the extraocular muscles had slipped from its position; in all cases the clinical impression of a slipped muscle was confirmed at re-operation.

The characteristic features of this type of muscle loss are: an initially satisfactory surgical result which over a few hours develops a marked squint with incomitance. Diagnostic criteria included large over or under correction, limited eye movement in one direction, and widening of the palpebral fissure in the field of limited duction.

GROUP 4

Cases of facial or orbital injury. In this group the muscle was damaged during facial trauma and became detached from the eye because of blunt or penetrating trauma.

\section{Results}

\section{PEROPERATIVE MUSCLE LOSS (GROUP 1)}

There were four patients with peroperative loss of a muscle. In two cases (cases 1 and 2) the muscle was relocated at the time of initial surgery and in two (cases 3 and 4) the muscle was not found until at least one re-exploration had been performed (Table 1). In all instances the lost muscle was the medial rectus. Three cases were undergoing a resection procedure for exotropia and the remaining one a recession for esotropia. In all cases the muscles had been cut from the

Table 1 Peroperative muscle loss

\begin{tabular}{|c|c|c|c|c|}
\hline Case & Surgery & Muscle & Surgery & Outcome \\
\hline 1 & $\begin{array}{l}\text { MR+ } \\
\text { LR- }\end{array}$ & MR & 3 surgeons - found muscle & Good \\
\hline 2 & $\begin{array}{l}\text { MR+ } \\
\mathrm{LR}-\end{array}$ & MR & $\begin{array}{l}2 \text { surgeons - found } \\
\text { muscle }\end{array}$ & Good \\
\hline 3 & $\begin{array}{l}\text { MR- } \\
\mathrm{LR+}\end{array}$ & MR & $\begin{array}{l}\text { Unable to relocate muscle. } \\
\text { Re-exploration } 1 \text { not found. } \\
\text { Re-exploration } 2 \text { found. }\end{array}$ & Good \\
\hline 4 & $\begin{array}{l}\text { MR+ } \\
\text { LR- }\end{array}$ & MR & $\begin{array}{l}\text { Unable to relocate muscle. } \\
\text { Transposition nasal slips of } \\
\text { IR and SR }\end{array}$ & $\begin{array}{l}45 \mathrm{D} \text { exo. } \\
\text { AHP. } \\
\text { No adduct }\end{array}$ \\
\hline
\end{tabular}

Finally full nasal transposition with $5 \mathrm{~mm}$ resection of the IR and SR - good result.

$M R=$ medial rectus $; \mathrm{LR}=$ lateral rectus $; \mathrm{IR}=$ inferior rectus; $\mathrm{SR}$ superior rectus; + = resected; $-=$ recessed; $\mathrm{AHP}=$ abnormal head posture; $\mathrm{D}=$ prism dioptre: exo=exotropia. globe as part of the surgical procedure and during the course of this the sutures had either been cut out or become disinserted from the muscle allowing it to retract into the orbit.

In both cases that were relocated at the time of the initial surgery, one of the authors was present in the operating theatre and was able to relocate the missing muscle. It was found to be extremely useful to have the assistance of the surgeon who had lost the muscle. His knowledge of the circumstances leading up to the loss provided valuable information enabling the muscle to be relocated.

The other cases were referred postoperatively following failure to relocate the affected muscle. In case 3 the medial rectus fell off the muscle hook during a marginal myotomy. It was not relocated at the first exploration but computed tomography (CT) scans demonstrated that it remained attached to the globe (Fig 4) and was relocated at the second re-exploration.

In case 4 when the medial rectus was not found the nasal halves of the inferior and superior rectus muscles had been transposed to the anatomical insertion of the medial rectus muscle in an attempt to obtain some postoperative adducting force. However when the patient was referred she had a 45 dioptre exotropia with no adduction (Fig 5) and was attempting to maintain binocular vision with a marked abnormal head posture (Fig 6). In addition the medial conjunctiva was severely scarred and heaped up (Figs 5 and 6) because of extensive dissection while attempting to relocate the missing muscle. CT indicated that the medial rectus had retracted into the orbit with no attachment to the globe. Re-exploration proved virtually impossible because of the scarring affecting the tissue planes and transposed vertical rectus muscles. Ultimately a full transposition of the vertical recti muscles was undertaken with an associated resection of these muscles and a satisfactory result was obtained.

\section{INTRAOPERATIVE SNAPPING (GROUP 2)}

Five muscles snapped during the course of squint surgery. These muscles had been involved in previous surgery or were associated with presumed extraocular muscle pathology (Table 2). At the time they were being held without excessive force on a muscle hook when the muscle simply tore across its belly and retracted. In case 5 the patient had undergone multiple extraocular muscle operations to the affected eye in the region of the snapped superior rectus muscle.

The muscle was noted clinically to be pale and inelastic in case 6 and the pathology report on a biopsy specimen indicated that there was an increase in the interfibre connective tissue with the presence of some abnormal muscle fibres. The inferior rectus muscle in case 7 had been involved in a blow-out fracture and the muscle had been damaged at the time of the injury.

Case 8 had undergone superior oblique resections and antero-placements for IV nerve palsies with a resultant acquired Brown's syndrome. The superior rectus muscle snapped during the second operation to correct the troublesome 


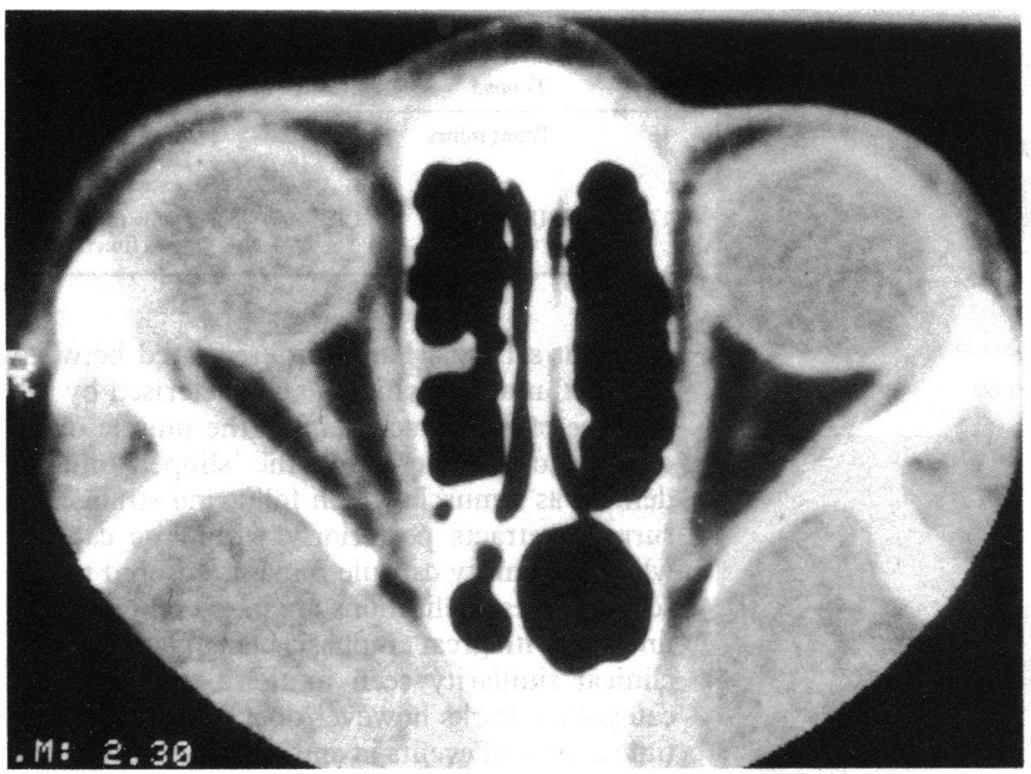

Figure 4 CT scan demonstrating that the right medial rectus remains attached to the eye by tenuous attachments.

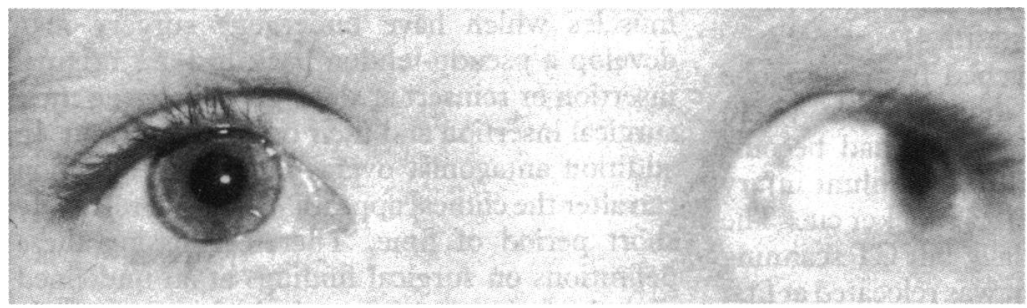

Figure 5 Manifest exotropia with no adduction. The medial conjunctiva in the right eye is heaped up and results in a cosmetic blemish.

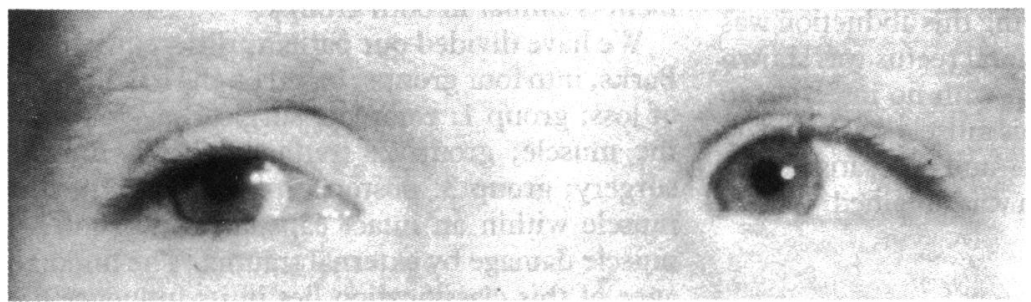

Figure 6 Maintenance of binocularity in the same child as Fig 5 is by adoption of an abnormal head posture.
Table 2 Intraoperative snapping

\begin{tabular}{|c|c|c|c|c|}
\hline Case & Pathology & Surgery & Muscle & Position \\
\hline 5 & $\begin{array}{l}\text { IVN palsy } \\
\text { previous surgery }\end{array}$ & SO tuck & SR & Relocated \\
\hline 6 & Rubella (congenital) & $\begin{array}{l}\text { MR- } \\
\text { MR- }\end{array}$ & MR & Relocated \\
\hline 7 & Blow-out fracture & $\begin{array}{l}\text { IR- } \\
\text { SR- }\end{array}$ & IR & Relocated \\
\hline 8 & Previous surgery & SO & SR & Relocated \\
\hline 9 & $\begin{array}{l}\text { Long standing } \\
\text { VI palsy after } \\
\text { BTXA }\end{array}$ & MR- & MR & $\begin{array}{l}\text { Relocated. } \\
\text { Fragmented } \\
\text { muscle }\end{array}$ \\
\hline
\end{tabular}

$\mathrm{SO}=$ superior oblique $; \mathrm{BTXA}=$ botulinum toxin $\mathrm{A}$

had undergone adjustable squint surgery and the remainder had undergone a standard nonadjustable procedure.

Re-exploration in all cases revealed that the capsule of the muscle was attached to the globe by the sutures and the belly of the muscle was found retracted inside its capsule $5-6 \mathrm{~mm}$ behind its intended new insertion (except case 15 in which surgical exploration was delayed for some months). The muscle was easily relocated in all cases and the postoperative results were good overall.

Immediate exploration was performed as soon as the diagnosis was made. However in case 14 the patient did not re-present himself until 2 weeks after surgery despite his mother having noted the secondary divergence and limited adduction of the left eye during the first postoperative day (Figs 7,8 ). The muscle was successfully re-located but some residual postoperative limitation of adduction remained and forced duction testing at a second procedure revealed a degree of lateral rectus contracture. This was treated with recession of the lateral rectus with resultant improvement in angle and range of movement.

In case 15 the delay in exploration was longer (5 months) and the muscle was found to have slipped posteriorly to $17 \mathrm{~mm}$ from the limbus.

Table 3 Postoperative slip

\begin{tabular}{|c|c|c|c|c|}
\hline Case & Surgery & Muscle & Clinical course & Outcome \\
\hline 10 & $\begin{array}{l}\text { LR- } \\
\text { MR+ } \\
\text { (adj.) }\end{array}$ & MR & $\begin{array}{l}\text { Adjusted day } 1 \text {. Good } \\
\text { position. No adduction } \\
\text { beyond midline at } 1 \\
\text { week }\end{array}$ & $\begin{array}{l}\text { Muscle } \\
\text { relocated }\end{array}$ \\
\hline 11 & $\begin{array}{l}\text { MR- } \\
\text { LR+ } \\
\text { (adj.) }\end{array}$ & MR & $\begin{array}{l}\text { Adjusted day } 1 \text {. Good } \\
\text { position. Diplopia all } \\
\text { positions on day } 3 \text {. } \\
\text { Limited adduction }\end{array}$ & $\begin{array}{l}\text { Muscle } \\
\text { relocated }\end{array}$ \\
\hline 12 & $\begin{array}{l}\text { MR- } \\
\text { LR+ } \\
\text { (adj.) }\end{array}$ & MR & $\begin{array}{l}\text { Adjusted day 1. Good } \\
\text { position. Diplopia all } \\
\text { positions day } 2 \text {. } \\
\text { Limited adduction }\end{array}$ & $\begin{array}{l}\text { Muscle } \\
\text { relocated }\end{array}$ \\
\hline 13 & $\begin{array}{l}\text { MR- } \\
\text { LR+ }\end{array}$ & MR & $\begin{array}{l}\text { Late evening (day of } \\
\text { surgery) straight. lst } \\
\text { morning postop } \\
\text { diplopia and no } \\
\text { adduction }\end{array}$ & $\begin{array}{l}\text { Muscle } \\
\text { relocated }\end{array}$ \\
\hline 14 & $\begin{array}{l}\text { MR- } \\
\text { MR- }\end{array}$ & MR & $\begin{array}{l}\text { 1st day postop. Eye } \\
\text { straight. Later that day } \\
\text { noted to be exotropic } \\
\text { (by mother). Not } \\
\text { reviewed for } 2 / 52\end{array}$ & $\begin{array}{l}\text { Muscle } \\
\text { relocated } \\
\text { limited } \\
\text { adduction }\end{array}$ \\
\hline 15 & $\begin{array}{l}\text { MR- } \\
\text { MR- }\end{array}$ & MR & $\begin{array}{l}\text { Divergent postop. } \\
\text { Limited adduction. } \\
\text { Explored } 5 \text { months later }\end{array}$ & $\begin{array}{l}\text { Muscle } \\
\text { relocated } \\
17 \mathrm{~mm} \\
\text { from } \\
\text { limbus. } \\
\text { Re-advanced }\end{array}$ \\
\hline
\end{tabular}

POSTOPERATIVE SLIP (GROUP 3)

There were six muscles which slipped in the immediate postoperative period (Table 3 ). The affected muscle was the medial rectus in all cases. In three patients (cases 10,11 and 12) the patient torsion. Pathological examination demonstrated mild degenerative changes only. The last case in this group (case 10) had a long standing VIth nerve palsy (at least 30 years) and following two and during the attempt to recess this muscle it crumbled away from the retaining hook. The

The affected muscle in this group was not restricted to that of the medial rectus but all four uscles were involved. In all cases the muscle was successfully re-located although in one case one re-exploration was required.

.




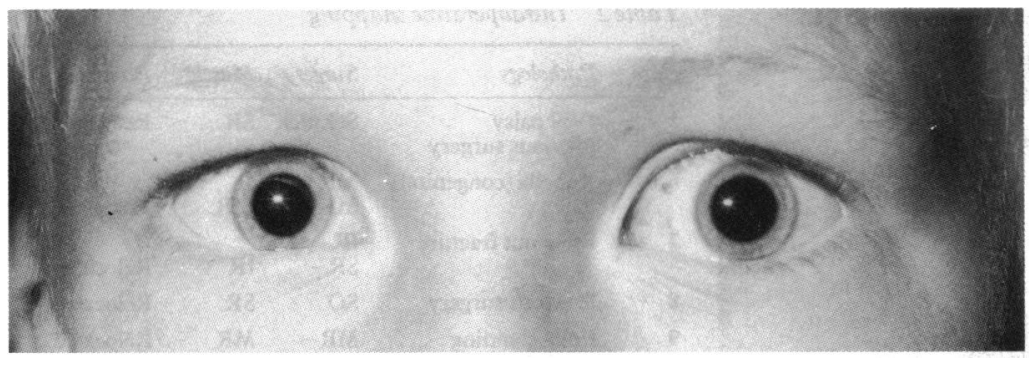

Figure 7 Secondary divergence after slippage of the left medial rectus.

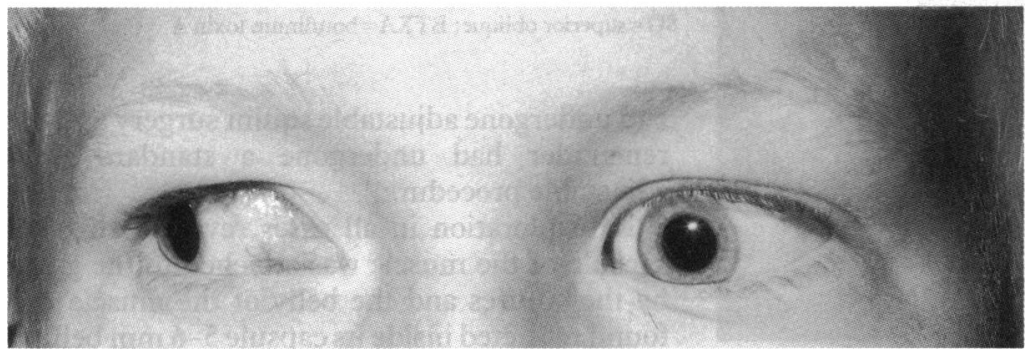

Figure 8 Limited adduction of left eye due to postoperative slip of the medial rectus (same patient as in Fig 7).

TRAUMATIC MUSCLE LOSS (GROUP 4)

Two muscles became detached from the globe during the course of an injury (Table 4). In case 16 the medial rectus muscle had become damaged in what appeared to be a blunt injury when the eye was struck with a snooker cue. The muscle was not found initially but CT scanning identified its presence and it was relocated at first re-exploration (Fig 9).

The rotating end of an electric drill injured the lateral aspect of the right eye in an industrial accident in case 17. Following this abduction was severely limited and the lateral rectus was shown on CT scan to be very thin with no insertion to the globe demonstable. This muscle was partially relocated at exploration and a satisfactory improvement of abduction was obtained.

Figure 9 CT scan demonstrating retracted left medial rectus which retains some attachments to the eye. A tuft of muscle is seen at the insertion.

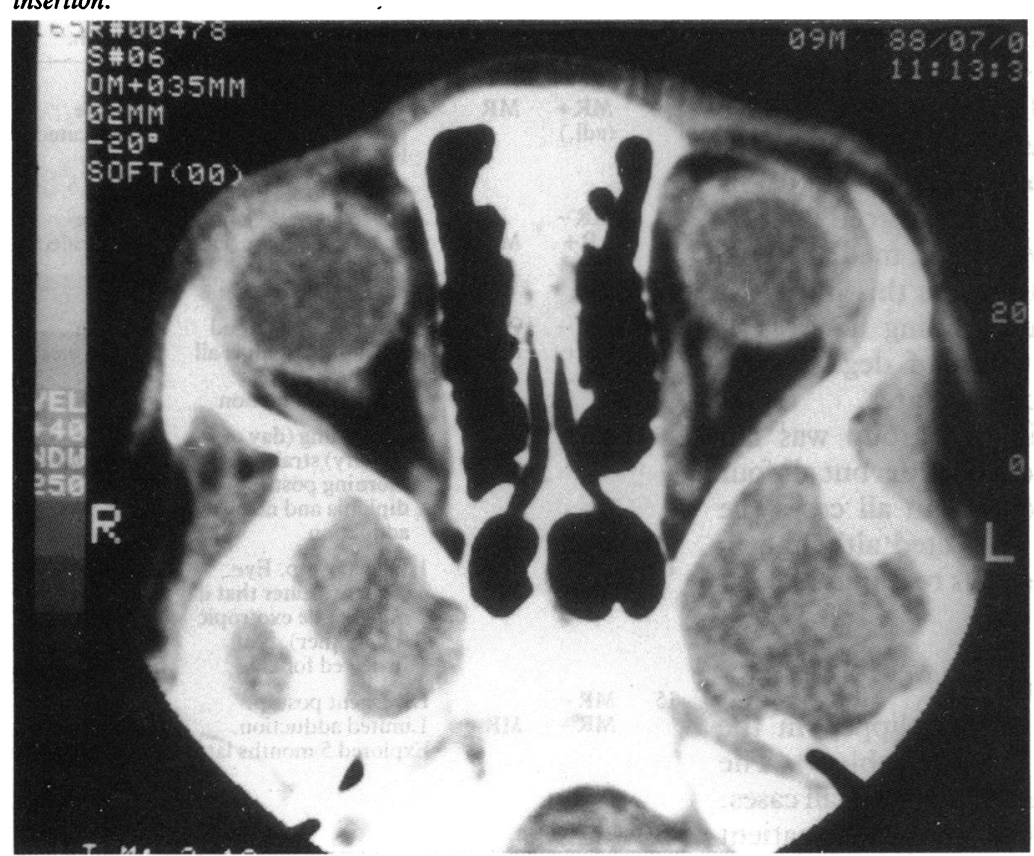

Table 4 Traumatic muscle loss

\begin{tabular}{llll}
\hline Case & Trauma & Muscle & Outcome \\
\hline 16 & Blunt injury & MR & $\begin{array}{l}\text { Not found - } \\
\text { LR recessed. } \\
\text { Re-explored - found } \\
\text { Partially relocated - } \\
\text { good function }\end{array}$ \\
\hline
\end{tabular}

different settings. Parks differentiated between the 'lost' muscle, which he characterised by the absence of any attachment of the muscle or its capsule to the sclera' and the 'slipped' muscle defined as a muscle which following strabismus surgery retracts posteriorly within its capsule while the empty capsule remains sutured to the sclera. ${ }^{2}$ These definitions are based on operative findings with great emphasis being placed on the clinical similarity seen in these two different categories. Parks however does not indicate the time course of events in any of his papers on this subject and many of his patients in both categories had undergone surgery in the distant past. It is well recognised that over a period of time muscles which have undergone surgery may develop a pseudo-tendon back to their original insertion or reinsert at some point between their surgical insertion and their original insertion. In addition antagonist overaction and contraction can alter the clinical appearances over a relatively short period of time. Therefore basing these definitions on surgical findings at an undefined period of time postoperatively is not entirely satisfactory especially when the clinical findings tend to overlap to such a degree and the management is similar in both groups.

We have divided our patients differently from Parks, into four groups, based on the mechanism of loss: group 1: complete surgical severance of the muscle; group 2: traumatic break during surgery; group 3: postoperative slippage of the muscle within an intact capsule; and group 4: muscle damage by external trauma. The importance of this classification lies in its influence on the management and prognosis of the condition.

Muscles which are cut surgically, having been dissected from their surrounding fascia in the course of squint surgery, clearly have a poor prognosis for relocation (group 1). The three other categories are likely to do much better. The snapped muscles (group 2) or traumatically damaged muscles (group 4) do not rupture all of their fibres and also retain fascial attachments to the eye thus allowing them to be more easily relocated. The value of these fascial attachments to the globe is emphasised by the finding that the medial rectus was the muscle that was 'lost' in all cases in group 1. This result is in keeping with the findings of Plager and Parks who found that the majority of medial recti in their series were irretrievable.' The superior, lateral, and inferior recti are all attached to the globe via their adjacent oblique muscles. The medial rectus is the only muscle which can freely retract into the orbit. Undoubtedly other rectus muscles are dropped during surgery but they are usually easily found by tracing their connections to adjacent oblique muscles.

The muscle which slips postoperatively (group 3) retains an attachment to the globe in a 


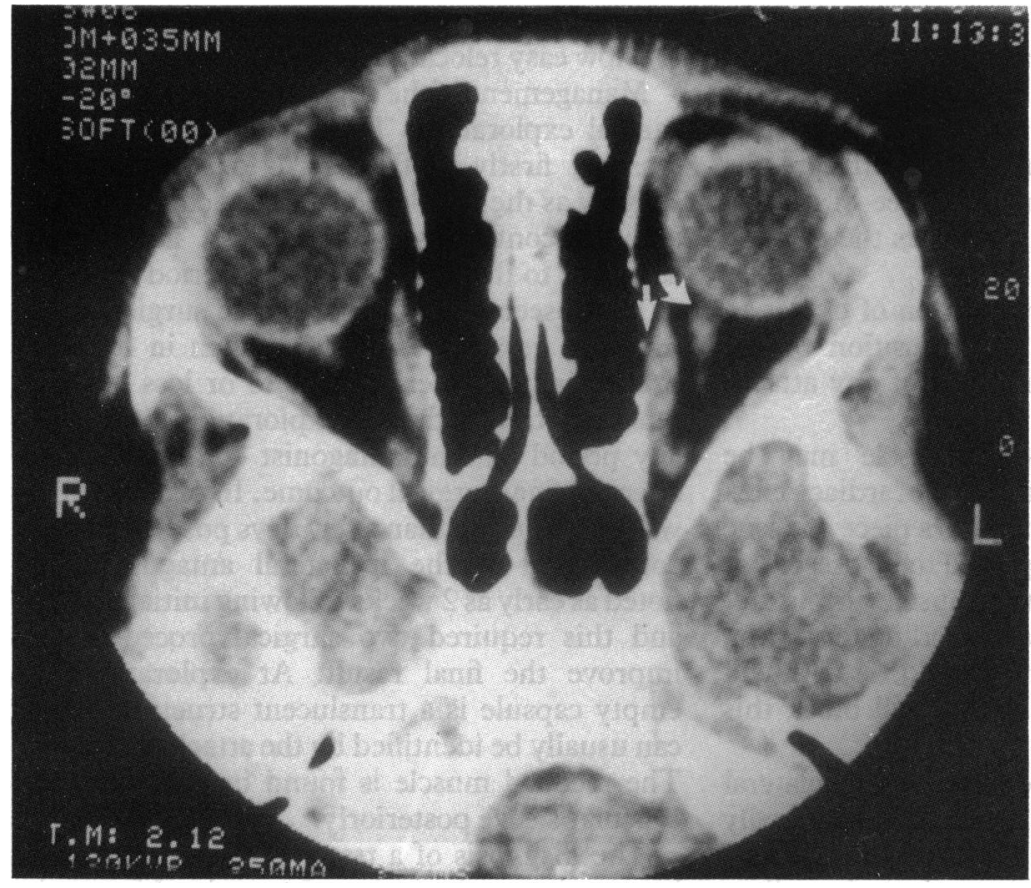

Figure 10 The line of exploration should follow the straight arrow along the medial rectus. Following around the globe leads to the optic nerve. different manner, by means of its capsule. Postoperative slippage is a situation which occurs when the muscle is not fully included in the locking sutures. ${ }^{2}$ Instead the suture is passed superficially into the muscle capsule but does not pass through the fibres of the muscle. This results in a satisfactory appearance and position of the muscle at the time of surgery. In the early postoperative period however when muscle function returns and the fibres contract the belly of the muscle retracts within the anchored fibrous capsule. Exploration of slipped muscles within 1 week of surgery reveals that the muscle capsule alone is attached to the globe and the muscle belly can be located posteriorly within this sheath. The characteristic clinical picture is that of an acceptable surgical result immediately postoperatively with a good range of ocular movements; however an increasing angle of squint develops with incomitance and associated limitation in rotations in the early postoperative period of hours to days.

It is interesting to note that all of our slipped muscles were medial recti. Furthermore all but one had been recessed. We are unable to determine whether the increased risk of slippage is a function of the medial rectus per se or of the muscle having been recessed. Our impression is that recession is the responsible mechanism as in this procedure the suture is passed through the insertion rather than the belly of the muscle making the placement of the suture through the muscle body less well defined.

Three of the cases of slipped muscles had surgery carried out using the adjustable suture technique. It is unlikely that the loss was due to the method used as in all cases the adjustment on the first day proved to be straightforward and adequate and it was in the period of time following this that the slippage took place.

The muscles which traumatically ruptured during surgery had other pathology or had undergone previous surgery. In no case was excessive traction or force used to hold the muscle. The muscle which snaps across its width leaves a small tuft of the insertion attached to the globe and frequently retains fibres or capsule attached to the part of the muscle which has retracted. In addition the check ligaments have not usually been dissected away. This type of damaged muscle may prove difficulty to reattach to the globe due to fragmentation of the muscle during suturing.

Losing a muscle not only results in a cosmetic problem but can cause constant diplopia in adults which may be compensated by an abnormal head posture. In addition children undergoing surgery for a potentially binocular result may lose the stimulus to develop or obtain binocular responses at a period when they are most susceptible.

\section{Management}

Any muscle lost peroperatively should if possible be retrieved during that operation as this provides the best possible chance of a good outcome. This applies both to snapped muscles and to cut muscles. At the time of surgery ideally two experienced assistants should be present to assist with the exploration. They should provide good exposure using malleable retractors to open up the fascial planes. One common problem that is frequently encountered is that the direction of search followed is around the globe rather than directly backwards along the line of the medial rectus (Fig 10). If dissection takes place around the globe then optic nerve damage is likely as this is the first structure to be encountered. To locate the medial rectus the direction of exploration should be parallel to the medial wall of the orbit following the muscle's anatomical line.

In most cases the operating miscoscope is a useful tool to help identify any muscle fibres. It is of the utmost importance that the fascial planes are not damaged when dissecting posteriorly through the muscle sleeve as orbital fat adherence and scarring can easily be produced. If the muscle cannot be identified clearly it is useful to attach the adjacent fascia to the globe and recess the ipsilateral antagonist, the amount being based on the springback test. At this stage we do not recommend that transposition surgery is carried out. If the ipsilateral antagonist has already undergone surgical recession or resection prior to loss of the muscle then the only transposition option available (to ensure against anterior segment ischaemia) is movement of the nasal halves of the inferior and superior recti to the medial rectus insertion. This procedure does not provide adequate adduction (see case 4 ) and in addition re-exploration of such cases is almost impossible because of scarring, adherence, and damage to the fascial planes. In essence if this operation is performed then it is extremely difficult for the future intervention to be successful. This has been recommended as the surgical procedure of choice, ${ }^{2}$ but the resultant adduction when used for the lost medial rectus (case 4) was disappointing. Transposition of the complete superior and inferior rectus muscles medially is also unlikely to produce adequate adduction (unless combined with a resection of these vertical recti). If combined with a recession of 
the ipsilateral lateral rectus this procedure is likely to cause anterior segment ischaemic in adults. Therefore at this first stage we recommend recession of the ipsilateral antagonist with attachment of fascia to the medial rectus insertion as this may allow a degree of muscle activity and guide the way towards the missing muscle.

CT scanning is the investigation of choice in order to determine the exact position of the muscle and presence or absence of any attachment to the eye.

Location of the missing muscle may be assisted by utilisation of the oculocardiac reflex as follows. ${ }^{5}$ Traction is applied to a piece of tissue in which the muscle is suspected to be present; if this tissue does contain the muscle the oculocardiac reflex will be activated leading to slowing of the pulse rate. Atropine should be withheld from the pre-medication as this will block this reflex. ${ }^{5}$

If the muscle cannot be found the ipsilateral lateral rectus muscle should be maximally recessed on hang-back sutures and fascia attached to the medial rectus insertion. Stay sutures should be placed through the superior and interior rectus insertions and passed through the lid medially holding the eye in maximal adduction for 6 weeks.

If the eye remains exotropic, further surgery would consist of a complete medial transposition of the vertical recti. In order to obtain any valuable degree of adduction both muscles should also have a $5 \mathrm{~mm}$ resection. In older patients preoperative anterior segment fluorescein angiography should be performed to assess the risks of anterior segment ischaemia. If there is any delay between operative procedures great care should be taken to assess the ocular rotations using forced duction and spring-back tests as secondary contracture, and in children sensory realignment, may continue to take place.

There are several surgical techniques which reduce the likelihood of muscle loss. These include (1) careful full thickness locking bites of each muscle suture, care being taken not to insert the sutures too superficially into capsule only; this is assisted by spreading the muscle well on a Chavasse hook; (2) removal of anterior Tenon's capsule so that the muscle can be clearly visualised; (3) multiple small cuts when detaching the muscle from the globe rather than one large snip; and (4) some authors have suggested that the majority of the posterior intermuscular septum and check ligaments should be left intact in order to allow easy relocation of a lost muscle. ${ }^{6}$

Management of the slipped muscle is early and careful exploration. This is important for two reasons: firstly, with regard to the timing of surgery as the fragile capsular attachments of an actively contracting muscle may not remain adherent to the globe for a long period (see case 15); and secondly, with regard to surgical technique as great care must be taken in order to prevent any further damage to or loss of these tenuous strands during exploration. If left for any period of time antagonist contraction may alter the final surgical outcome. In case 14 which was left for more than a few days postoperatively contracture of the ipsilateral antagonist was noted as early as 2 weeks following initial surgery and this required two surgical procedures to improve the final result. At exploration the empty capsule is a translucent structure which can usually be identified by the attached sutures. The recoiled muscle is found by following the capsular sleeve posteriorly.

The diagnosis of a traumatically ruptured or lacerated muscle is based on the history in association with CT scan results and the findings at surgery. In patients with traumatic extraocular muscle imbalance this injury must be differentiated from the restrictive type of abnormality seen in blow-out fractures or weakness secondary to haematoma formation. The muscle may be damaged either as a result of blunt or penetrating trauma. CT scans are essential in making the diagnosis and in determining the location of the muscle prior to exploration.

In summary there are different mechanisms of extraocular muscle loss with different likely outcomes. Relocation of the slipped, snapped, or traumatically ruptured or severed muscle is in general successful. The medial rectus muscle which is lost during squint surgery causes particular problems in relocation.

We would like to thank Bernadette McCarry for her assistance and Angela Ellingford for help with the illustrations.

1 Plager DA, Parks MM. Recognition and repair of the 'lost' rectus muscle. A report of 25 cases. Ophthalmology 1990; 97: 131-7.

2 Plager DA, Parks MM. Recognition and repair of the slipped rectus muscle. F Paediatr Ophthalmol Strabismus 1988; 25: 207-74.

3 Scott AB. Disinserted extraocular muscles. Am $\mathcal{f}$ Ophthalmol 1975; 79: 289-91.

4 Helveston EM, Grossmann RD. Extra-ocular muscle lacerations. Am $\mathcal{F}$ Ophthalmol 1976; 81: 754-60.

5 Apt L, Isenberg SJ. The ocular cardiac reflex as a surgical aid in identifying a slipped or 'lost' extra-ocular muscle. $\mathrm{Br} \mathcal{F}$ Ophthalmol 1980; 64: 362-5.

6 Wright KW. Discussion on recognition and repair of the lost rectus muscle. Ophthalmologv 1990; 97: 136-7. 